
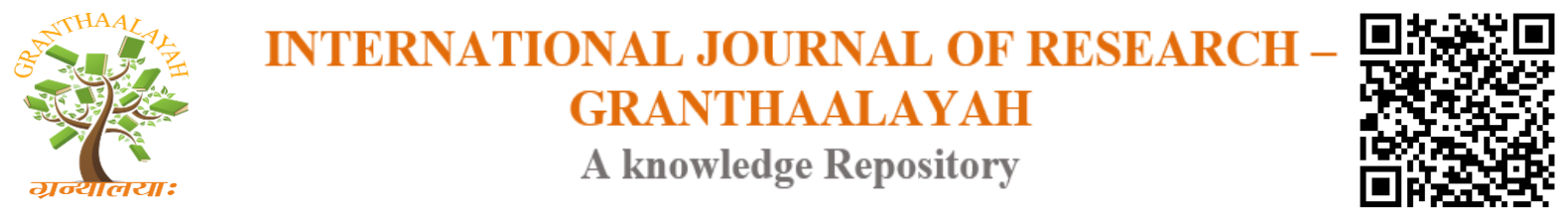

Science

\title{
BIOLOGICAL CONTROL OF CITRUS WOOLLY WHITE FLY ALEUROTHRIXUS FLOCCOSUS MASK (HOMOPTERA: ALEYRODIDAE) BY CALES NOACKI HOW (HYMENOPTERA: APHELINIDAE) IN SOME TANZANIAN SMALL-SCALE CITRUS ORCHARDS
}

\author{
Zuberi Singano Seguni ${ }^{* 1}$, Oscar Mfugale ${ }^{2}$ \\ ${ }^{*}$ Mikocheni Agricultural Research Institute P. O. Box 6226 Dar es Salaam TANZANIA \\ ${ }^{2}$ Biological Control Centre, Kibaha, TANZANIA
}

DOI: https://doi.org/10.29121/granthaalayah.v4.i6.2016.2641

\section{ABSTRACT}

Cales noacki How (Hymenoptera: Aphelinidae) wwas released in citrus groves in Muheza $\left(05^{\circ} 10^{\prime} \mathrm{OS}, 38^{\circ} 46^{\prime} \mathrm{OE}\right)$ and Morogoro $\left(06^{\circ} 4^{\prime} 0^{\prime \prime} S, 37^{\circ} 40^{\prime} \mathrm{O}\right.$ E) Townships to control Aleurothrixus floccosus Mask (Homoptera: Alleyrodidae). Sleeve cage and "free release" methods were used to introduce the parasitoid onto selected citrus trees. $C$. noacki adults and mummies were released at selected sites between 08:00 and 09:30 am on 14th September 1999. Adults were first observed 90 days after introduction. They were also recovered from 2 nd and 3rd CWWF instars. At Morogoro, CWWF infestations by adults, eggs and nymphs were reduced by between 6 and 12 fold 90 days after release and between 30 and 300 fold 60 months after. At Muheza decreases were between 140 and 700 and 12 and 17 fold, respectively compared. Parasitoid recovery indicated its establishment. Recoveries were also on trees up to two kilometres away from release sites. Parasitoid release was also accompanied by vigour improvement of previously heavily infested citrus trees. This is the first report of successful use of C. noacki for control of A. floccosus in Tanzania, which was prevented from spreading from the original small infestation foci.

Keywords:

$C W W F=$ Citrus Woolly White Fly; Cale noacki.

Cite This Article: Zuberi Singano Seguni, and Oscar Mfugale, "BIOLOGICAL CONTROL OF CITRUS WOOLLY WHITE FLY ALEUROTHRIXUS FLOCCOSUS MASK (HOMOPTERA: ALEYRODIDAE) BY CALES NOACKI HOW (HYMENOPTERA: APHELINIDAE) IN SOME TANZANIAN SMALL-SCALE CITRUS ORCHARDS" International Journal of Research - Granthaalayah, Vol. 4, No. 6 (2016): 82-91. 


\section{INTRODUCTION}

The citrus woolly white fly, Aleurothrixus floccosus Mask (CWWF) was accidentally introduced into Eastern Africa, probably from the Mediterranean region and North Africa, where citrus is an important cash crop. In this region, the pest had earlier caused severe crop losses in the 1970s in Morocco (Abbasi, 1975), Egypt (Vulic and Betran, 1977) and more recently in Ethiopia (Alemu et al, 2014).

The presence of A. floccosus in Tanzania was first reported near Tengeru in Arusha, by Brigitte Nyambo in 1993, and later at Morogoro around Sokoine University of Agricultural Sciences (Lohr, personal communication). Specimens collected by B. Nyambo were later identified by $\mathrm{CIE}$ as the citrus woolly white fly. Since then, the pest has been reported in some citrus-growing areas of Morogoro Township (Mwaiko and Kyamba, 1995). A new isolated infestation was also discovered in Muheza Township in Tanga region (Seguni, 1998). Sporadic pest presence was also reported in small areas of Kilimanjaro region (Lohr, 1997) and Shinyanga and Dodoma (Mfugale, personal communication). However, the pest was not detected at Kyela, which neighbours Malawi where CWWF has been reported (Lohr, 1997). The pest was also discovered in small numbers on orange and lemon trees at Wanging'ombe in Njombe region (Seguni own observation, 2003).

The presence of CWWF in Morogoro and Muheza districts in particular posed a potential threat to the Tanzanian citrus industry if the new pest would not be immediately controlled in the few and small infestation foci. Moreover, the pest had become a new element in the indigenous homopteran pest complex, for which no sustainable control measures are undertaken. The presence of the pest in Morogoro and Muheza Townships, both surrounded by important citrus growing areas producing more than 250,000 metric tons annually (DALDOs Office Muheza District Council, 2016), was threatening the heart of the citrus industry which is a dependable source of district revenues and rural economies of these areas.

CWWF affects citrus trees by the adults' and nymphs' feeding effects on tender leaves thus depriving the plant of vital manufactured nutrients. However, more significant is the sooty mould that develops on leaves on residues of honeydew that is produced copiously by the pest, which reduces significantly the photosynthetic ability of infested plants, leading to leaf fall, senescence and eventual death of severely infested plants. Control of CWWF by various insecticides has been attempted (David 2002) but is largely impractical (Lohr, 1997) because the infestation occurs wholly on the underside of leaves where accessibility to insecticides is limited. Moreover, the frequency of sprays required for effective control of the pest would make the method expensive and unacceptable environmentally. In addition, most smallholder farmers growing most of the citrus are unable to purchase insecticides and the spraying gear.

The use of the oligophagous parasitic wasp, Cales noacki How (Hymenoptera, Aphelinidae) (Carl, 1995) is an effective and sustainable biological control method against A. floccosus. The parasitoid was earlier used successfully against the pest in the Mediterranean region, saving the industry from virtual collapse (Carrero, 1975; Magalhaes, 1980; Liotta and Maniglia, 1984). In East Africa the parasitoid was used successfully in Uganda and Kenya in 1996 (Lohr, Seif and Nang'ayo, personal communication). In both countries, the parasitoid established and spread in 
citrus groves very quickly after only a couple of months, effecting good control over CWWF. To curb spread of the pest from spreading from the relatively small foci a research project to introduce the parasitoid was executed between 1999 and 2004.

\section{METHODS}

Colonies of CWWF for raising $\mathrm{C}$. nocki were reared on caged young potted orange seedlings at the Kibaha Biological Control Station (KBCS) in April 1999 from cultures of adult insects collected from citrus groves in Morogoro between April and May 1999. By June 1999, wellestablished CWWF colonies in the screen house were ready for inoculation with $\mathrm{C}$. noacki. Between May and June 1999, baseline surveys of CWWF infestation levels were conducted in the Morogoro and Muheza Townships and surrounding areas. The surveys were also aimed at selecting suitable sites for initial release of the parasitoid. A shipment of C. noacki was made in Mid September 1999, part of which was reared on CWWF in the screen house at KBCS and part introduced directly in the field at Morogoro and Muheza (Seguni, 1999).

\subsection{FIELD EVALUATION OF CWWF INFESTATION AND INCIDENCE OF OTHER CITRUS PESTS AND NATURAL ENEMIES}

Evaluation of CWWF population was according to Lohr, (1997); Mwaiko and Kyamba, (1995) and Seguni, (1998). Samples of 10 trees were taken randomly per orchard, but in an area where citrus was scattered, individual trees were considered along roadside transects. The same trees were used for the survey throughout the period of the experiment. From each of the four poles of a tree i.e. north, south, east and west, four leaves: two tender and two older, were inspected for about 5 minutes for different life stages of CWWF. Adult white flies were quickly counted using a counter while eggs and larval instars were estimated according to the area on leaf undersides each of the sedentary larval stages covered as follows: from zero indicating absence to 100 indicating entire leaf surface covered. Old CWWF attack was recorded as present (1) or absent (0). Other pests and natural enemies on the trees were noted down and where possible, classified to genus level or simply by their common names.

\subsection{FIELD INTRODUCTION OF C. NOACKI}

Both the sleeve cage (Plates1and 2) and the open or 'free release' methods were used in releasing adult parasitoids and mummies respectively. Grease was smeared on both ends of the branch on which the cage was mounted to prevent noxious insects, particularly ants, from getting into the cage. Cages were untied two weeks after parasitoid release. A total of 120 and $180 \mathrm{C}$. noacki adults in glass vials from icipe were transported in cool boxes to release sites in Muheza $\left(05^{\circ} 10^{\prime}\right.$ OS, 38 $46^{\prime} \mathrm{OE}$ ) and Morogoro (06 49' $0^{\prime \prime} \mathrm{S}, 37^{\circ} 40^{\prime} 0^{\prime \prime} \mathrm{E}$ ), respectively. In addition, the release at Muheza also included mummies on three infested leaves. The glass vials were supplied with thinly honey-smeared strips of paper as food for the adult wasps. The cool boxes stocked with blocks of ice were aimed at reducing the parasitoids' temperature and thus their metabolic activity in order to increase their survival prior to release.

Parasitoids at Muheza were released by one team of researchers on two orange trees at the district headquarters and by a second team of researchers on five orange trees at the Prison's 
citrus orchard in Morogoro Township at 09:00 am on the 14th of September 1999. Subsequent open releases were done on 11th October 1999 at Morogoro and between 18th October and 8th December 1999 on same and new trees at Muheza.

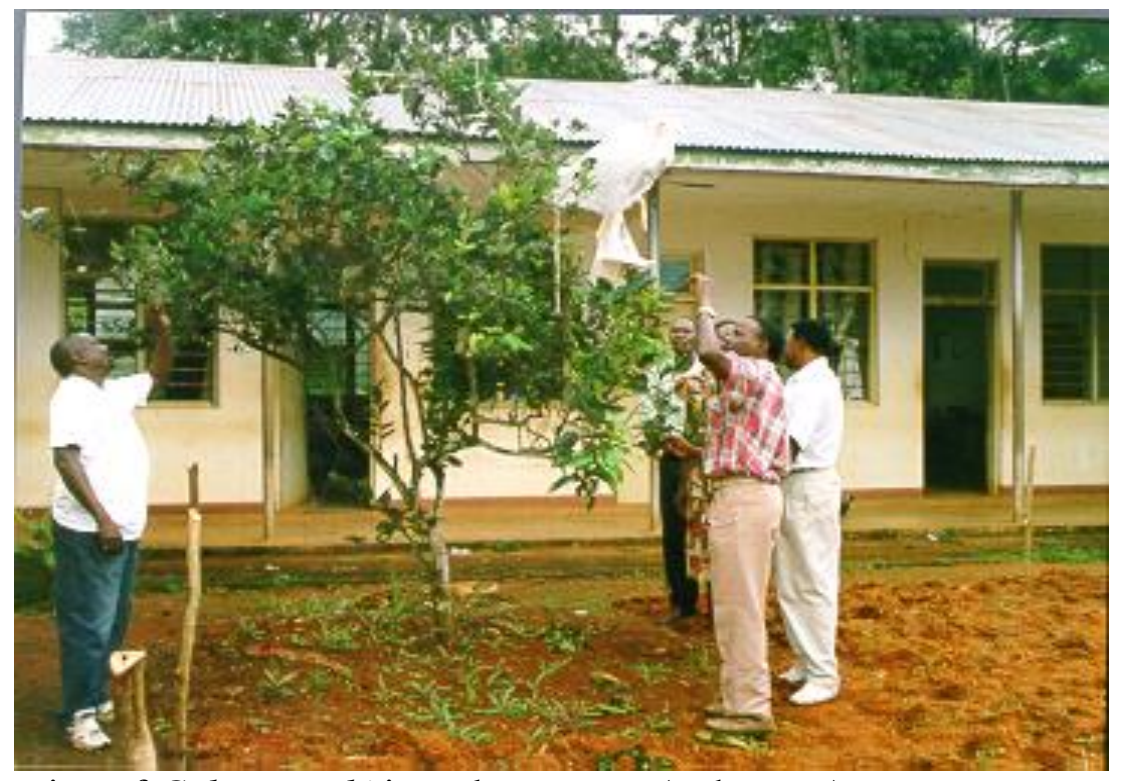

Plate 1: Releasing of Cales noacki in a sleeve cage (red arrow) on an orange tree at Muheza District Block in mid September 1999

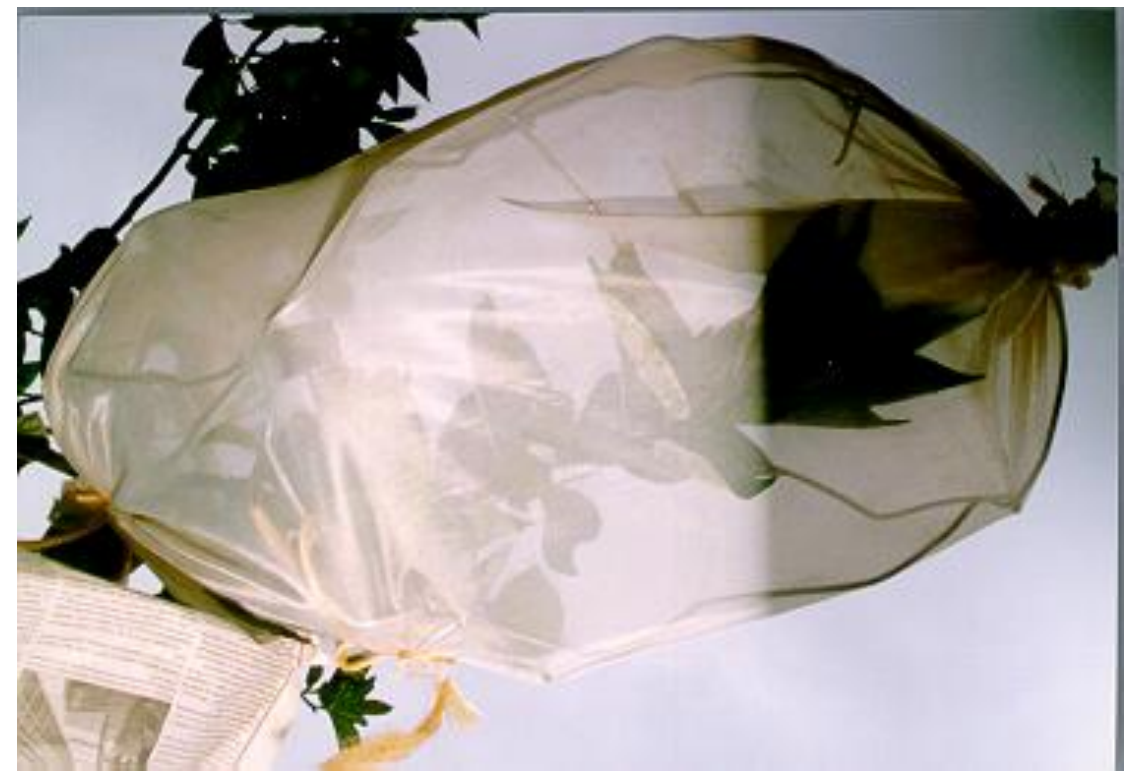

Plate 2: Close view of a sleeve cage

\subsection{FIELD MONITORING OF C. NOACKI}

Detailed monitoring of C. noacki establishment started in December 1999 approximately 90 days after initial introduction. Monitoring was delayed to allow sufficient time for multiplication of 
the parasitoid. Direct quick counts of adult parasitoids were done on CWWF-infested leaves in the crown of ten sample trees by two observers using counters each working on one half of the crown. The numbers of observed adults in a period of five minutes were added up for each tree and then pooled for all observed trees and expressed as adults per tree. In addition, mummified CWWF were collected from infested trees and placed in paper bags for incubation in the laboratory at ambient temperatures for three to four days, during which time emerging parasitoids were counted under a stereomicroscope. Most reliable information, however, was by direct tree crown observations due to scarcity of mummified CWWF at sampling time resulting from depletion of CWWF by C. noacki. Data was analysed by the chi square test at the $95 \%$ probability level.

\section{RESULTS}

\subsection{DEVELOPMENT OF CALES NOACKI POPULATION IN CITRUS ORCHARDS WHERE IT WAS INTRODUCED IN MID SEPTEMBER 1999 IN MUHEZA AND MOROGORO TOWNSHIPS}

Adults of C. noacki were first sampled in detail at both release sites at the end of December 1999, nearly 90 days after its initial release (Table 1). The population increased most rapidly between May 2000 and March 2001, especially at Muheza. Thereafter, the population of adult parasitoids decreased at both sites whereby in April 2004, sixty months after initial release of the parasitoid, none could be found on citrus. The decrease in the number of parasitoids corresponded with a marked decrease in all stages of CWWF (Table 3). If the two sites are compared, the population of C. noacki increased faster at Muheza than at Morogoro during the same observation period (Table 1). This could possibly have been attributed due to higher temperatures at Muheza (150-200 masl) favouring faster parasitoid development compared to Morogoro (525 masl). CWWF and C. noacki population fluctuations were in line with pestparasite rhythms (Southwood, 1976). There must have been higher numbers of adult parasitoids in the tree crowns which were possibly naturally missed by the observers due to their minute size.

Table 1: Number of Cales noacki adults per tree $(\mathrm{n}=10)$ observed on citrus tree crowns at different sampling dates following its release in mid September 1999 in Muheza and Morogoro Townships

\begin{tabular}{llcc}
\hline Period & Sampling dates & Muheza & Morogoro \\
\hline At Cales noacki release & September 1999 & 0 & 0 \\
Post C. noacki release & December 1999 & 6.6 & 3 \\
& May 2000 & 15 & 7 \\
& March 2001 & 14 & 3 \\
& July 2001 & 6 & 4 \\
& January 2002 & 2 & 3 \\
& July 2003 & 3 & 2 \\
& April 2004 & 0 & 0 \\
\hline
\end{tabular}




\subsection{STATUS OF CWWF ON CITRUS TREES BEFORE AND AFTER RELEASE OF CALES NOACKI IN MUHEZA AND MOROGORO TOWNSHIPS}

The status of CWWF prior to establishment of $C$. noacki is presented in Table 2, which shows that the pest was abundant both at Muheza and Morogoro. Eight months after initial and subsequent parasitoid releases, significant reduction in the population of all growth stages of CWWF occurred at both sites (Table 2) $(\mathrm{P} \leq 0.001$; Chi square value for trend at Muheza $=$ 1006.9 at one degree of freedom). At Morogoro, the population of different growth stages of CWWF continued to decrease sharply and between July 2001 and April 2004 the pest became severely reduced (Table 2); $(\mathrm{P} \leq 0.001$; Chi square value for trend $=388.87$ at one degree of freedom). The CWWF population trends at Morogoro and Muheza were similar except between September 2001 and January 2002 when minor increases were observed at the latter before marked decreases occurred between July 2003 and April 2004 (Table 2).

Table 2: Mean numbers of and citrus leaf areas occupied by different developmental stages of CWWF on citrus trees prior to release of Cales noacki in Morogoro and Muheza Townships

\begin{tabular}{llllll}
\hline & \multicolumn{4}{l}{ Numbers } & \multicolumn{4}{l}{ Leaf area occupied by: } \\
\hline Sampling date & Site & Adults & Eggs & Nymphs & Old CWWF \\
Mid Sep1999 & Morogoro & 88 & 107.2 & 355.7 & 12.2 \\
Mid Sep1999 & Muheza & 68.1 & 72.8 & 135.1 & 4.5 \\
\hline
\end{tabular}

Table 3: Mean numbers of and citrus leaf areas occupied by different developmental stages of CWWF on citrus trees on different sampling dates after release of Cales noacki in Morogoro and Muheza Townships

\begin{tabular}{llrrr}
\hline & Numbers & \multicolumn{2}{l}{ Leaf area occupied by: } & \\
\hline Sampling date & Adults & Eggs & Nymphs & Old CWWF \\
\hline Morogoro & & & & \\
May 2000 & 8.2 & 9.1 & 56.9 & 15 \\
March 2001 & 1.5 & 2.4 & 5.7 & 0 \\
July 2001 & 0.2 & 0.6 & 0.3 & 0 \\
January 2002 & 0 & 0 & 0 & 0 \\
July 2003 & 0.9 & 0.3 & 0.2 & 0 \\
April 2004 & 0.2 & 0 & 0 & 1 \\
& & & & \\
Muheza & & 0.1 & 1 & 0 \\
May 2000 & 0.1 & 1 & 4.3 & 0 \\
April 2001 & 3.7 & 0.6 & 15.4 & 1.1 \\
Sept 2001 & 2.3 & 27.5 & 28.3 & 3.3 \\
January 2002 & 13 & 0.1 & 0 & 0 \\
July 2003 & 0.2 & 0 & 0.6 & 0.3 \\
April 2004 & 0.2 & & & \\
\hline
\end{tabular}




\section{DISCUSSION}

The trend of decreasing numbers of CWWF at both release sites corresponded with increasing numbers of $\mathrm{C}$. noacki adults in citrus tree crowns, which suggested impact of the parasitoid on CWWF population. The changes in parasitoid and CWWF numbers were in general agreement with the pest-parasitoid dynamics, whereby to a certain degree, CWWF abundance favoured rapid parasitoid population build-up until at such level that low numbers of CWWF became a limiting factor for parasitoid multiplication, thus lowering its population. It is expected that the dynamic pest-parasitoid relationship will remain favourable unless some adverse factors are imposed such as farmers using insecticides unwisely thus upsetting the parasitoid numbers. Such pest-parasitoid interactions are discussed in detail by Waage et al, 1985; Wright and Verkerk, 1995 and Tang and Cheke, 2008).

Successful release and establishment of C. noacki against A. floccosus on citrus trees in Morogoro and Muheza Townships in Tanzania had resulted in rapid reduction in the population of the pest in areas where the parasitoid had initially established. Similar results were obtained in Uganda and Kenya where the parasitoid was earlier released (Ssekyawa, 1995; Nang'ayo 1996 personal communication); in South Portugual Magalhaes, G. S. (1980) and in the Mediterranean region where the citrus industry was saved from collapse (Liotta and Maniglia, 1984). Other workers who reported effective use of C. noacki against CWWF include Delbene and Gargani, 1991; Vivas, 1992; Barbagallo et al., 1993 and Katsoyannos et al., 1997). In Tanzania, the parasitoid became established very quickly on introduced and neighbouring citrus trees. The prompt introduction of the parasitoid in the relatively small infestation foci had resulted in containment of the pest in relatively small areas, preventing it from spreading and attaining serious pest outbreaks in new areas, which is indicated by absence of recent reports of serious pest outbreak in new areas.

It was not easy to relate directly the effect of reduced citrus infestation by CWWF due to establishment of C. noacki and fruit production because CWWF is not a direct pest. Moreover, in experimental areas citrus is most often subjected to a wide range of similarly damaging homopteran pests such as black flies, scales and aphids which were abundant on the citrus trees. However, at Muheza 7-10 years old orange trees that were prior to release of C. noacki heavily infested by CWWF and which had ceased fruit bearing, had resumed growth vigour and orange production (Plate 3 ). 


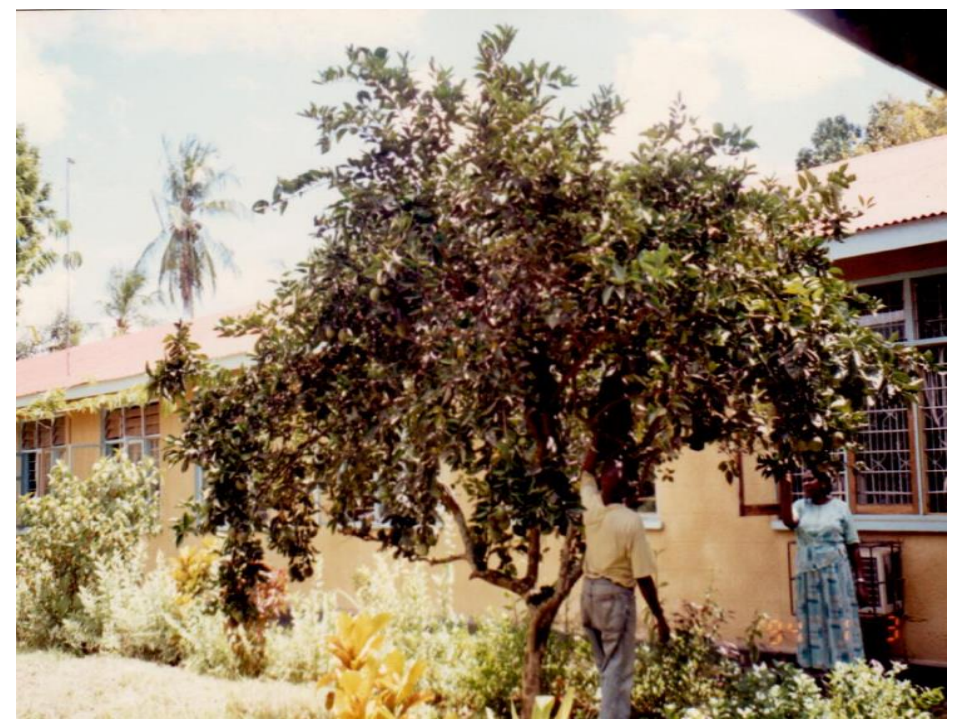

Plate 3: Revisited orange tree 60 months after release of Cales noacki at the Muheza District Block

A wide range of insect pests occurred on citrus trees of which the black fly, Aleurocanthus woglumi Ashby, leaf miner and scale insects were the commonest (Table 4). Where these produced honeydew, as for instance A. woglumi, the ant Pheidole megacephala Fabricius was the most dominant attendant followed in some groves by Anoplolepis custodiens and Camponotus sp complex. Several unidentified indigenous predators notably ladybird beetles and hoverflies also occurred on citrus. An exotic parasitoid, Eretmoceros serius Silv was observed amidst colonies of the black fly in all surveyed areas.

Presence in the citrus cropping systems of abundant indigenous and exotic fauna of parasitoids and predators was an indication of a balanced agro-ecosystem, which should be maintained through periodic updating of the inventory of the economic pests and their natural enemies with a view to develop augmentative or classical biological control strategies, which in combination with cultural practices should sustain environment-friendly production of citrus in Tanzania.

It is not clear from our observations whether introduction of CWWF and its subsequent reduction by $C$. noacki has had an impact on the population and distribution of indigenous pests and natural enemies. However, it would be expected that a competition must have occurred between pests that similarly infested citrus such as between the black fly and CWWF. Occurrence in several citrus areas of $E$. serius was interesting and showed that biological control programs should be undertaken as regional initiatives because the wasp was initially released around Mombasa Kenya in the 1950s (Hill, 1975) and must have spread naturally into Tanzania from there.

There were some indigenous predators notably ladybird beetles that had become adapted to CWWF, but these have not been identified nor their effect on the pest evaluated. They are likely to be generalists. The major indigenous foraging ant species $P$. magacephala, Camponotus $s p$ complex, A. custodiens and in a few cases Oecophylla longinoda, had become very well adapted to collecting honeydew from CWWF in addition to that produced by indigenous Homoptera such 
as aphids, scale insects, mealy bugs and black flies. These are likely to foster non beneficial associations with injurious homoptera.

\section{CONCLUSION AND RECOMMENDATIONS}

In conclusion, this research provided proof of successful establishment of $C$. noacki in experimental citrus groves and that the parasitoid had profound impact on CWWF which became severely reduced. Reduction in CWWF infestation pressure on heavily infested citrus trees had resulted in rejuvenation of the trees, which were brought back to vigour and production. The biological control effected by the parasitoid benefited small-holder citrus groves in release areas and beyond as the parasitoid spread spontaneously without further human intervention. However, to safeguard the parasitoid farmers have been urged to refrain from unwise use of contact insecticides.

\section{ACKNOWLEDGEMENTS}

Many thanks are to the GTZ IMP Project ICIPE Nairobi Kenya and the Ministry of Agriculture Livestock and Fisheries for financing the research activities. Thanks are also to different farmers and extension staff in project areas for cooperation. Last but not least to my colleagues in Pest Control Unit: Valentina Nyange, C. Materu, K. Lema and G. Mwingira and collaborators at KBCS in particular Joyce Kiboya for dedicated work. Last but not least I would like to regretfully $\mathrm{m}$ oan the untimely death of the co author who passed away sometime in 2014 when this paper was being prepared.

\section{REFERENCES}

[1] Abbasi, M. (1975). Presence au Maroc d'une nouvelle espece d'aleurode Aleurothrixus flocossus Maskell (Homoptera, Aleyrodidae). Fruits 30, 173-176.

[2] Alemu Nega, Emana Geti and Teman Hussein (2014). Integrated Management of Woolly White Fly Aleurothrixus flocossus (Homoptera: Aleyrodidae) on citrus at Adama, East Shewa Zone Ethiopia. Journal of Biology, Agriculture and Healthcare, Vol 4 no 23:1-21

[3] Barbagallo, S., S. Longo, C. Rapisarda and G. Siscaro. 1993. Status of the biological control against citrus whiteflies and scale insects in Italy. Proc. Int. Soc. Citriculture. 3: 1216-1220

[4] Bohlen, E.(1978). Crop Pests in Tanzania and their Control. German Agency for Technical Cooperation, Verlag Paul Parey Berlin and Hamburg, 142 Pp.

[5] Carl, K. (1995). Host spectrum of Cales noacki How. And Amitus spiniferus Breth. parasitoids of the white fly Aleurothrixus floccosus Mask. IIBC European Station

[6] Carerro, J. M. (1975). Primera contribucion al estudio de la mosca blanca de los agrios Aleurothrixus flocossus Mask. en la region, Valenciana. Agosto 1972 eneo 1974,: Anales del instituto Nacioanal de Investigaciones Agrarias , Serie: Proteccion Vegetal, 5,. 145235

[7] David L. Kerns. Insecticidal Control of Woolly Whiteflies1: http://ag.arizona.edu/pubs/crops/az1303. 
[8] Delbene, G. and E. Gargani., 1991. Observation of Aleurothrixus floccosus (Mask.) (Hom.: Aleyrodidae) and its antagonists Cales noacki Howard. (Hymnoptera: Aphelinidae) in Toscana. Redia. 74: $11-126$

[9] Denis J Wright and Robert H. J Verkerk (1995). Integration of chemical and biological control systems for arthropods: Evaluation in a multi-trophic context. Pesticide Science 44: $207-218$

[10] Elfring, W. (1988). Production and Marketing of Fruits in the Lowland Areas of Tanga Region Republic of Tanzania. A consultancy Study. GTZ Project Nr. 77.21 1.78.01.120. 95Pp. (Unpublished)

[11] Hill, D. (1975). Agricultural Insect Pests of the Tropics and their Control. Cambridge University Press Cambridge. 516 Pp.

[12] J. K. Waage, M. P. Hassel and H. C. J Godfray (1985). The dynamics of pest-parasitoidinsecticide interactions. J. App. Ecology 22: 825-835

[13] KARI, (1990, 1991). Kenya Agricultural Research Institute, Annual Report 1990 and 1991. Nairobi Kenya.

[14] Katsoyannos, P., K. Ifantis and D. C. Kontodimas., 1997. Phenology, population trend and natural enemies of Aleurothrixus floccosus (Hom.: Aleyrodidae) at a newly invaded area in Athens, Greece. Entomophaga. 42: 619 - 628

[15] Lohr, B. (1997). A survey of major citrus pests in five countries of East and Central Africa with emphasis on the recently introduced Citrus Woolly White Fly. GTZ IPM Nairobi Kenya, 17 Pp (Unpublished)

[16] Magalhaes, G. S. (1980) Note on the introduction of Aleurothrixus floccosus (Homoptera, Aleyrodidae) in South Portugual and its control by Cales noacki (How.) (Hymenoptera, Aphelinidae) Proceedings of the International Symposium of IOBC/Wna.

[17] Mwaiko, W. S. and Kyamba, R. D. (1995). Survey of the woolly white fly, Aleurothrixus floccosus on citrus as a pest in major citrus growing areas in the United Republic of Tanzania (Unpublished)

[18] Sayi Tang and Robert A Cheke (2008). Mathematical Biosciences 215: 115-125

[19] Seguni, Z (1998). A survey of the Citrus Woolly White Fly, Aleurothrixus floccosus to clarify incidence and severity in Muheza and Kilosa Districts, 7Pp, (Unpublished).

[20] Seguni, Z. (1999). A Pre-release confirmatory survey of the Citrus Woolly White Fly, Aleurothrixus flocossus in Morogoro, Kilosa and Muheza Districts in Tanzania. Pp 8. (Unpublished)

[21] Seguni, Z. (2000). Release and Monitoring Establishment and Spread of Cales noacki in Citrus Orchards in the Mainland Tanzania. End of Project Phase Report. Pp 21(Unpublished)

[22] Southwood, T. R. E. (1976) Bionomics, strategies and population parameters in: R. M. May (ed.), Theoretical Ecology: Principles and applications. Blackwell, Oxford, pp. 3052

[23] Vivas, A. G. (1992) Present status of whitefly on citrus in Spain and control guidelines. Seminars commission technique, September, Antalya - Turkey, pp. 1 - 19

[24] Way, M. J. (1953b). The relationship between certain ant species with particular reference to biological control of the Coreid, Theraptus sp. Bulletin of Entomological Research 44: 669-691 